\title{
Effect of immune tolerance induced by immature dendritic cells and CTLA4-Ig on systemic lupus erythematosus: An in vivo study
}

\author{
CUILI HUANG ${ }^{1 *}$, LIDAN ZHANG $^{1 *}$, FANG LING $^{2 *}$, SIJIAN WEN $^{1}$, YANYAN LUO $^{1}$, HUI LIU $^{1}$, \\ JINGPING LIU ${ }^{1}$, WENJUN ZHENG ${ }^{1}$, MING LIANG ${ }^{1}$, JIAN SUN ${ }^{2}$ and YOU-KUN LIN ${ }^{1}$ \\ ${ }^{1}$ Department of Dermatology, First Affiliated Hospital of Guangxi Medical University; \\ ${ }^{2}$ Department of Cell Biology and Genetics, Guangxi Medical University, Nanning, Guangxi 530021, P.R. China
}

Received September 21, 2016; Accepted July 27, 2017

DOI: $10.3892 / \mathrm{etm} .2018 .5697$

\begin{abstract}
Systemic lupus erythematosus (SLE) is a multi-organ autoimmune disease in which tissue damage is caused by autoantibodies. The induction of specific immune tolerance, including the utilization of immune regulatory cells, may enhance the therapeutic effects of organ transplantation in patients with SLE. Furthermore, inhibiting immune responses has been reported to be an effective treatment for SLE. However, few studies have explored the association between an increased immune tolerance and a decreased immune response in SLE treatment. Dendritic cells (DCs), which are highly efficient antigen-presenting cells, are able to induce specific tolerance, while cytotoxic $\mathrm{T}$ lymphocyte antigen 4-immunoglobulin (CTLA4-Ig) inhibits the immune response. In the present study, interleukin (IL)-10-treated DCs and CTLA4-Ig were administered to mice with SLE alone or in combination and the therapeutic effects were investigated. IL-10 was added into the culture medium of bone marrow-derived DCs to prevent them from differentiating into mature cells. Low levels of major histocompatibility complex II, cluster of differentiation (CD)40, CD80 and CD86 were
\end{abstract}

Correspondence to: Dr You-Kun Lin, Department of Dermatology, First Affiliated Hospital of Guangxi Medical University, 6 Shuangyong Road, Nanning, Guangxi 530021, P.R. China

E-mail: linyoukun7@aliyun.com

Abbreviations: ANA, anti-nuclear antibody; APCs, antigen-presenting cells; DCs, dendritic cells, dsDNA, double-stranded DNA; IL, interleukin; MHC II, major histocompatibility complex II; PE, phycoerythrin; CTLA4-Ig, cytotoxic $\mathrm{T}$ lymphocyte antigen 4-immunoglobulin; rmGM-CSF, recombinant mouse granulocyte-macrophage colony-stimulating factor; SLE, systemic lupus erythematosus; Th, T helper cells; Treg, regulatory $\mathrm{T}$ cells

\section{${ }^{*}$ Contributed equally}

Key words: tolerance, immature dendritic cells, cytotoxic $\mathrm{T}$ lymphocyte antigen 4-immunoglobulin, interleukin-10, systemic lupus erythematosus detected, which indicated that the immature state of DCs was maintained. IL-10-treated DCs were subsequently injected into the caudal vein of B6.MRL-Fas ${ }^{\mathrm{ppr} / \mathrm{J}}$ lupus mice, which are an established animal model of SLE. To amplify the tolerance effect, mice were simultaneously injected with CTLA4-Ig. Compared with the IL-10-treated DC and CTLA4-Ig groups, combined treatment with IL-10-treated DCs and CTLA4-Ig strongly induced immune tolerance in mice with SLE, as indicated by the significantly reduced levels of urine protein, anti-nuclear antibody, double-stranded DNA and IL-17A. A significant decrease in the proportion of $\mathrm{T}$ helper cells and an increase in the proportion of $\mathrm{CD}^{+}$forkhead box protein $\mathrm{P}^{+}$ Treg cells was also observed, further confirming the induction of immune tolerance. These results suggest that combined treatment with IL-10-DCs and CTLA4-Ig may be a promising novel therapeutic strategy for the treatment of SLE.

\section{Introduction}

Systemic lupus erythematosus (SLE) is a systemic autoimmune disease with multi-organ involvement in which autoantibodies induce tissue damage (1). Immunosuppressive therapy with pharmacological agents, including mycophenolate mofetil (2) and cyclophosphamide (3), is widely used to improve the clinical outcomes of SLE. However, nonspecific suppression of the immune system and the associated side effects reduce patient quality of life (4). Several studies have aimed to induce specific tolerance to enhance the therapeutic effect of organ transplantation via utilizing immune regulatory cells, in particular antigen-presenting cells (APCs) $(5,6)$ and regulatory T cells (Tregs) (7). However, few reports have focused on the use of tolerogenic APCs as a therapeutic strategy for the treatment of SLE.

Dendritic cells (DCs) are highly efficient APCs that have been studied in rodents and humans $(8,9)$. DCs may be identified at immature and mature stages based on their phenotypic and functional characteristics (10). Mature DCs, which express high levels of major histocompatibility complex II (MHC II), cluster of differentiation (CD)80 and CD86 (11), secrete the T helper (Th) 1 cell-driving cytokine interleukin (IL)-12 (12). These molecules are essential for the $\mathrm{T}$ cell immunological response, which demonstrates that mature DCs serve an important role in the initiation of immune responses (13). 
Immature DCs express low levels of MHC II and co-stimulatory molecules, including CD40, CD80 and D86 (14), and have low $\mathrm{T}$ cell stimulatory ability. These cells are associated with $\mathrm{T}$ cell energy induction and Treg cell generation (15). In clinical practice, infusion with immature DCs, either alone or in combination with a co-stimulation blockade, regulates host $\mathrm{T}$ cell responses and effectively prolongs allograft survival (16-18). However, the maturity status of DCs is not stable as immature DCs differentiate into mature DCs when exposed to antigens and stimulation factors (19). Therefore, maintaining the status of immature DCs is key for the successful application of immature DCs in immunotherapy.

It has previously been reported that IL-10 is able to inhibit DC maturation (20), causing more IL-10 to be secreted by immature DCs; this feedback loop amplifies the tolerogenic effect of immature DCs. IL-10 therefore serves a pivotal role in the prevention of DC maturation and the induction of immune tolerance (21) during the progression of autoimmune disease or transplant rejection (22). In culture, DCs transduced with IL-10 have been demonstrated to have reduced levels of co-stimulatory molecules (CD80/CD86) and, furthermore, do not produce the potent allo-stimulatory cytokine IL-12 (23). A previous in vivo study revealed that animals which received IL-10-overexpressing DCs had a reduced incidence of skin graft rejection compared with animals that received DCs modified with a control virus, suggesting that there was reduced mononuclear cell infiltration and less dermo-epidermal junction destruction (24). In addition, IL-10-treated DCs inhibit antigen-specific immune responses in pre-activated immunocytes and these effects persist following repeated antigen restimulation (25). Immature DCs have been introduced as a therapy for SLE (26), and it has been reported that cytotoxic T lymphocyte-associated antigen 4-immunoglobulin (CTLA4-Ig) is able to induce immune suppression in autoimmune diseases (27) and organ transplantation (28). It was therefore hypothesized that the combination of immature DCs and CTLA4-Ig may effectively induce immune tolerance.

The aim of the present study was to explore the effect of DC-induced immune tolerance in SLE. Immature DCs, which were prevented from maturing using IL-10, were injected into the caudal vein of lupus-prone B6.MRL-Fas ${ }^{\mathrm{lpr}} / \mathrm{J}$ mice. The mice were also treated with CTLA4, which may serve to prevent the transmission of co-stimulatory signals and induce $\mathrm{T}$ cells to undergo apoptosis, become inactivated or anergic, thus inducing immune tolerance.

\section{Materials and methods}

Materials. Recombinant mouse granulocyte-macrophage colony-stimulating factor (rmGM-CSF), rmIL-10, and rmIL-4 were purchased from PeproTech, Inc. (Rocky Hill, NJ, USA). Mouse antibodies directed against CD40 (cat no. 11-0402-82), CD80 (cat no. 15-0801-82), CD86 (cat no. 12-0862-82), MHC II (cat no. 12-5321-82), IL-17A (cat no. 12-7177-81), IgG2a (cat no. 12-4321-80), CD4 (cat no. 11-0042-82) and forkhead box protein P3 (Foxp3; cat no. 12-4774-42) were purchased from eBioscience (Thermo Fisher Scientific, Inc., Waltham, MA, USA). rmCTLA4-Ig was purchased from R\&D Systems, Inc. (Minneapolis, MN, USA). RPMI-1640 medium and fetal bovine serum (FBS) was purchased from
Gibco (Thermo Fisher Scientific, Inc., Waltham, MA, USA). IL-17A (cat no. kt21287), anti-nuclear antibody (ANA; cat no. kt40119), and double-stranded (ds)DNA (cat no. kt21274) ELISA kits were purchased from MSK Biological Technology, Ltd. (Wuhan, Hubei, China).

B6.MRL-Fas ${ }^{\mathrm{lpr}} / \mathrm{J}$ lupus mice were purchased from the Model Animal Research Center of Nanjing University (Nanjing, China). C57Bl/6J mice were purchased from Hunan SJA Laboratory Animals Co., Ltd. (Changsha, Hunan, China).

Immature DC culture. All experiments used in the present study were approved by the Ethical Review Committee of the First Affiliated Hospital of Guangxi Medical University (Nanning, China), and all experimental procedures were conducted in conformity with the institutional guidelines for the care and use of laboratory animals. All surgeries were performed under sodium pentobarbital (Merck KGaA, Darmstadt, Germany) anesthesia.

All mice were housed in an SPF level lab under controlled a temperature of $20-24^{\circ} \mathrm{C}$ and a relative humidity of $50-60 \%$ with a $12 / 12 \mathrm{~h}$ light-dark cycle. All of them had free access to formula feed and water.

A total of 10 female B6.MRL-Fas ${ }^{\text {lpr }} / \mathrm{J}$ lupus mice (2-months-old; weighing 18-20 g) were sacrificed, following which femurs and tibias were carefully harvested under aseptic conditions. Mouse bone marrow cells were collected by flushing the medullary cavity gently using RPMI-1640 medium supplemented with $10 \%$ FBS. The cells $\left(1 \times 10^{6}\right.$ cells $\left./ \mathrm{ml}\right)$ were transferred into 6-well plates $(2 \mathrm{ml} /$ well $)$ and incubated at $37^{\circ} \mathrm{C}$ in an humidified atmosphere containing 5\% $\mathrm{CO}_{2}$ for 4-6 h. Non-adherent cells were removed and $2 \mathrm{ml}$ RPMI-1640 with $10 \% \mathrm{FBS}, 20 \mathrm{ng} / \mathrm{ml} \mathrm{rmGM}-\mathrm{CSF}$ and $10 \mathrm{ng} / \mathrm{ml} \mathrm{rmIL-4}$ was added to each well. The medium was replaced every other day. At 5 days, IL-10 (10 ng/ml) was added to the medium, and cells were cultured for an additional 1 and 4 days until day 6 (6-IL-10-DC group) or day 9 (9-IL-10-DC group), respectively. Non-treated cells were also cultured for 6 days (D6-DC group) or 9 days (D9-DC group). Changes in the morphology and number of cells in the four groups were observed using an inverted microscope. A total of 10 high power fields of vision (magnification, x200) from each group were chosen randomly to count the cell numbers. The expression of CD80, CD86, MHC II and CD40 was examined using flow cytometry to identify the purity and maturity of the cells. Prior to detection, cells $\left(1 \times 10^{7}\right.$ cells $\left./ \mathrm{ml}\right)$ were washed with PBS 3 times $(5 \mathrm{~min}$ each time). Fc receptor-blocking pharmacon (1:50; eBioscience; cat no. MFCR00-4; Thermo Fisher Scientific, Inc) was added into the reaction tube and incubated for $15 \mathrm{~min}$ at $4^{\circ} \mathrm{C}$. All primary antibodies, including CD80 (cat no. 15-0801-82), CD86 (cat no. 12-0862-82), MHC II (cat no. 12-5321-82) and CD40 ( cat no. 11-0402-82; all Thermo Fisher Scientific, Inc.) were directly labeled with phycoerythrin or fluorescein isothiocyanate. Each antibody was incubated for $30 \mathrm{~min}$ at room temperature. Samples with the added antibody (CD80, 1:50; CD86, 1:50; MHC II, 1:200 and CD40, 1:200) were incubated at room temperature in the dark for $30 \mathrm{~min}$. The cells were washed with PBS 3 times, cells were fixed in paraformaldehyde (1:50) at $4^{\circ} \mathrm{C}$ and analyzed using a FACS Calibur flow cytometer within 24 h. Data were quantified using FCS software (version no. 4.0; BD Biosciences, Franklin Lakes, NJ, USA). 
SLE mouse treatment. A total of 24 4-month-old female B6. MRL-Fas ${ }^{\mathrm{lpr}} / \mathrm{J}$ lupus mice weighing 18-20 g were randomly divided into the following groups ( $n=6 /$ group): IL-10-DC group; CTLA4-Ig group; IL-10-DCs + CTLA4-Ig group; and PBS group. Mice were administered with $0.1 \mathrm{ml}$ IL-10-treated DCs $\left(1 \times 10^{8}\right.$ cells $\left./ \mathrm{ml}\right), 0.1 \mathrm{ml}$ CTLA4-Ig $(100 \mu \mathrm{g} / \mathrm{ml}), 0.1 \mathrm{ml}$ mixture of IL-10-treated DCs and CTLA4-Ig, or $0.1 \mathrm{ml} \mathrm{PBS}$ $(1 \mathrm{M} / \mathrm{l})$ via the tail vein. The normal group included 6 female $\mathrm{C} 57 \mathrm{Bl} / 6 \mathrm{~J}$ mice weighing 24-27 $\mathrm{g}$ with no interventions. All interventions were repeated at 0,2, 4 and 6 weeks. Housing conditions were as described above.

Biochemical analysis. Samples of urine and serum from SLE and normal mice were collected 2 days prior to the first intervention and 2 weeks following the last intervention. Mice were fasted for $12 \mathrm{~h}$ and transferred to metabolic cages prior to urine collection. During the $24 \mathrm{~h}$ collection period, urine was collected every $6 \mathrm{~h}$ via collecting tubes, the samples were centrifuged at $108 \mathrm{x}$ g for $5 \mathrm{~min}$ at room temperature to remove impurities and the supernatant was collected and stored at $4^{\circ} \mathrm{C}$ for further experiments. Urine proteins (Shanghai Enzyme-linked Biotechnology Co., Ltd.; cat no. 1037585, Shanghai, China) were detected using an automatic biochemical analyzer according to the manufacturer's protocol. The concentrations of IL-17A (MSK, cat no. kt21287, Wuhan, Hubei, China), ANA (MSK, cat no. kt40119, Wuhan, Hubei, China) and dsDNA (MSK, cat no. kt21274, Wuhan, Hubei, China) antibodies in the serum were detected using ELISA kits according to the manufacturer's protocol.

Lymphocyte separation. Mice in each group were sacrificed at 2 weeks following the last intervention. Spleens were harvested and macerated in RPMI-1640 with 4\% FBS. Spleen cells were filtered and lymphocytes were collected using density gradient centrifugation. Spleen cells suspension was added to the lymphocyte separation medium at a ratio of $1: 1$. The cell mixture was divided into 4 layers following centrifugation at $672 \mathrm{x}$ g for $20 \mathrm{~min}$ at room temperature. The second layer solution was extracted (counting from top to bottom) by washing twice with PBS at 1:6 ratio and centrifuged at $168 \mathrm{x}$ g for $10 \mathrm{~min}$ at room temperature. After discarding the PBS, spleen lymphocytes were collected and resuspended in RPMI-1640 at a density of $2 \times 10^{6}$ cells $/ \mathrm{ml}$.

Th17 cell detection. The proportion of Th17 cells out of the lymphocytes derived from SLE mouse spleens was quantified. Briefly, cell suspensions $\left(2 \times 10^{6}\right.$ cells $\left./ \mathrm{ml}\right)$ were added into centrifuge tubes $(0.5 \mathrm{ml})$ with phorbol 12-myristate 13-acetate (1:40) (Shanghai Yisheng Biotechnology Co. Ltd, cat no. 50601ES02, Shanghai, China), ionomycin (1:50) and brefeldin A (1:50), and incubated for $4 \mathrm{~h}$ at $37^{\circ} \mathrm{C}$. Cells were washed with PBS and centrifuged at $168 \mathrm{x}$ g for $5 \mathrm{~min}$ at room temperature. Prior to incubation with antibodies, Fc receptor-blocking pharmacon (1:50) (eBioscience, cat no. MFCR00-4, Thermo Fisher Scientific, Inc.) was added and incubated for $15 \mathrm{~min}$ at $4^{\circ} \mathrm{C}$. CD4 antibodies (1:200; eBioscience, cat no. 12-0041-82, Thermo Fisher Scientific, Inc.) were subsequently added to the cell suspensions and incubated at $4^{\circ} \mathrm{C}$ in the dark for $30 \mathrm{~min}$. Cells were washed with permeabilization buffer (eBioscience, cat no. 00-8333-56,
Thermo Fisher Scientific, Inc.) and centrifuged at $168 \mathrm{x} \mathrm{g}$ for $5 \mathrm{~min}$ at $4^{\circ} \mathrm{C}$. Subsequently, fixation/permeabilization solution (1:100; eBioscience, cat no. 00-5123-43, Thermo Fisher Scientific, Inc.) was added and the suspension was incubated for $45 \mathrm{~min}$ at $4^{\circ} \mathrm{C}$ in the dark. Cells were washed with permeabilization buffer (eBioscience, cat no 00-8333-56, Thermo Fisher Scientific, Inc.) and centrifuged at $168 \mathrm{x} \mathrm{g}$ for $5 \mathrm{~min}$. Fc receptor-blocking pharmacon (1:50) was added secondly and incubated for $15 \mathrm{~min}$. IL-17A (1:100; eBioscience, cat no. 12-7177-81, Thermo Fisher Scientific, Inc.) antibodies or an isotype control IgG2a (1:100; eBioscience, cat no. 12-4321-80, Thermo Fisher Scientific, Inc.) antibodies were added to each tube, which were incubated for $15 \mathrm{~min}$ at $4^{\circ} \mathrm{C}$. Cells were subsequently washed with PBS and centrifuged at $168 \mathrm{x} \mathrm{g}$ for $5 \mathrm{~min}$ at $4^{\circ} \mathrm{C}$. The supernatant was discarded, and the cells were resuspended with $0.2 \mathrm{ml}$ paraformaldehyde $(1: 50)$ at $4^{\circ} \mathrm{C}$. The cells were analyzed by flow cytometry within $24 \mathrm{~h}$. Data were quantified using FCS software (version no. 4.0). CD4 ${ }^{+} \mathrm{IL}-17 \mathrm{~A}^{+}$ cells were identified as the Th17 cell subset.

Treg cell examination. A low proportion of Th17 cells and high proportion of Treg cells is an indicator of immune tolerance induced in vivo (29). Therefore, the proportion of Treg cells out of the lymphocytes derived from the mouse spleens was examined and the Th17/Treg cell ratio was analyzed to investigate the tolerogenic effect of combined treatment with IL-10-treated DCs and CTLA4-Ig in SLE. All preparation was controlled at $4^{\circ} \mathrm{C}$. Briefly, cell suspensions $\left(2 \times 10^{6}\right.$ cells $\left./ \mathrm{ml}\right)$ were added to tubes (1x $10^{6}$ cells/tube) and then Fc receptor-blocking pharmacon (1:50) ( cat no. MFCR00-4; Thermo Fisher Scientific, Inc) and CD4 (1:200) antibodies (eBioscience, cat no. 11-0042-82, Thermo Fisher Scientific, Inc.) were added to the reaction tubes and incubated for $30 \mathrm{~min}$ at $4^{\circ} \mathrm{C}$. Cells were washed with permeabilization buffer (eBioscience, cat no. 00-8333-56, Thermo Fisher Scientific, Inc.) and centrifuged at $168 \mathrm{x} g$ for $5 \mathrm{~min}$ at $4^{\circ} \mathrm{C}$. After fixation and permeabilization with fixation/permeabilization solution (1:100; eBioscience, cat no. 00-5123-43, Thermo Fisher Scientific, Inc.) for $45 \mathrm{~min}$, cells were washed with permeabilization buffer (cat no. 00-8333-56; eBioscience; Thermo Fisher Scientific, Inc.) and centrifuged at $168 \mathrm{x} g$ for $5 \mathrm{~min}$ at $4^{\circ} \mathrm{C}$. Fc receptor-blocking pharmacon was then added and incubated for $15 \mathrm{~min}$ at $4^{\circ} \mathrm{C}$. Foxp3 (1:100) (eBioscience, cat no. 12-4774-42, Thermo Fisher Scientific, Inc.) or $\lg$ G2a (1:100) (eBioscience, cat no. 12-4321-80, Thermo Fisher Scientific, Inc.) were added and incubated for $45 \mathrm{~min}$ at $4^{\circ} \mathrm{C}$. Cells were washed with permeabilization buffer and centrifuged at $168 \mathrm{x} \mathrm{g}$ for 5 min twice at $4^{\circ} \mathrm{C}$. The cells were fixed with $0.2 \mathrm{ml}$ paraformaldehyde (1:50) at $4^{\circ} \mathrm{C}$ and analyzed by flow cytometer within 24 h. CD ${ }^{+} \mathrm{Foxp}^{+}$cells were identified as the Treg cell subset, and $\mathrm{IgG} 2 \mathrm{a}$ was used as an isotype control.

Statistical analysis. All experiments were performed a minimum of three times with six replicate samples for each group. All data are presented as the mean \pm standard deviation. The homogeneity of variances in the data was calculated using Levene's test. One-way ANOVA was used to analyse the data. Multiple comparisons were conducted using Games-Howell and Student-Newman-Keuls tests for unequal and equal variances, respectively. $\mathrm{P}<0.05$ was considered to indicate a statistically significant difference. 




Figure 1. Immature DCs are induced by IL-10. The DC maturation state markers MHC II, CD40, CD86 and CD80 were detected using flow cytometry. DCs, dendritic cells; IL, interleukin; MHC II, major histocompatibility complex II; CD, cluster of differentiation; D6-DCs, DCs cultured until day 6; D9-DCs, DCs cultured until day 9; 6-IL-10-DCs; D6-DCs; treated with IL-10; 9-IL-10-DCs, D9-DCs treated with IL-10. ${ }^{\text {\% }} \mathrm{P}<0.05$ vs. the D6-DCs group, ${ }^{\$} \mathrm{P}<0.05$ vs. the D9-DCs group, ${ }^{, P}<0.05$ vs. the 6-IL-10-DCs group, ${ }^{\circledR} \mathrm{P}<0.05$ vs. the 9-IL-10-DCs group.

\section{Results}

Immature DCs are induced by $I L-10$. To identify the maturation state of DCs that were cultured with or without IL-10 in vitro, the DC maturation state markers MHC II, CD40, CD86 and CD80 were detected using flow cytometry. The results revealed that the expression of $\mathrm{MHC} \mathrm{II}, \mathrm{CD} 40, \mathrm{CD} 86$, and CD80 was significantly lower in IL-10-treated DCs compared with the non-treated DC groups $(\mathrm{P}<0.05$; Fig. 1). Furthermore, the expression of MHC II $(\mathrm{P}<0.05), \mathrm{CD} 80(\mathrm{P}<0.05)$ and CD86 $(\mathrm{P}<0.001)$ was significantly lower in D6-DCs compared with D9-DCs (Fig. 1), indicating that, even with exposure to IL-10, DCs are able to differentiate into mature DCs during long-term in vitro culture. Based on these results, D6-DCs were used for the in vivo study.

Immune tolerance is induced by IL-10-DCs and CTLA4-Ig. Urine protein levels of the mice were assessed using an automatic biochemical analyzer, whereas IL-17A, ANA and anti-dsDNA levels were analyzed using ELISA kits. No significant differences were observed in urine protein levels among the SLE groups prior to treatment (Fig. 2A). However, urine protein levels were significantly higher in the IL-10-DCs, CTLA4-Ig, IL-10-DCs + CTLA4-Ig and PBS groups compared with the normal group $(\mathrm{P}<0.05$; Fig. 2A). Following treatment, urine protein levels in the IL-10-DCs, CTLA4-Ig and IL-10-DCs + CTLA4-Ig groups were significantly lower compared with pre-treatment values $(\mathrm{P}<0.05)$ and the PBS group $(\mathrm{P}<0.05$; Fig. 2A). Post-intervention urine protein levels were significantly lower in the IL-10-DCs + CTLA4-Ig group compared with the IL-10-DCs and CTLA4-Ig groups $(\mathrm{P}<0.001)$, and were close to those in the normal group ( $\mathrm{P}>0.05$; Fig. 2A).

No significant difference was observed in IL-17A, ANA or dsDNA levels among the SLE groups prior to treatment (Fig. 2B-D); however, these levels were significantly higher in the IL-10-DCs, CTLA4-Ig, IL-10-DCs + CTLA4-Ig and PBS groups compared with the normal mouse group (Fig. 2B-D). Levels of IL-17A, ANA and dsDNA were significantly lower following treatment compared with pre-treatment in the IL-10-DC, CTLA4-Ig and IL-10-DCs + CTLA4-Ig groups $\left({ }^{\%} \mathrm{P}<0.05\right.$; Fig. 2B-D). Post-intervention the relative levels of IL-17A, ANA and dsDNA were significantly lower in the IL-10-DCs + CTLA4-Ig group compared with the other treatment groups (Fig. 2B-D). These results indicate that SLE activity was most reduced in the IL-10-DCs + CTLA4-Ig group and that immune tolerance was induced.

T cell responses. The proportions of Th17 and Treg cells, identified by IL-17A and Foxp3 expression, respectively, were analyzed using flow cytometry (Fig. 3). The results revealed that the proportion of Th17 cells was significantly lower in the IL-10-DCs, CTLA4-Ig and IL-10-DCs + CTLA4-Ig groups compared with the PBS group $(\mathrm{P}<0.05)$, whereas it was significantly higher in the treatment groups compared with the normal group $(\mathrm{P}<0.05$; Fig. $3 \mathrm{~B})$. Following treatment, the proportion of Th17 cells in the IL-10-DCs + CTLA4-Ig group was significantly lower compared with the IL-10-DC and CTLA4-Ig groups ( $\mathrm{P}<0.05$; Fig. 3B).

In contrast, the proportion of Treg cells was significantly higher in the IL-10-DCs, CTLA4-Ig and IL-10-DCs + CTLA4-Ig groups compared with the PBS group $(\mathrm{P}<0.05)$ and significantly lower compared with the normal group ( $\mathrm{P}<0.05$; , Fig. 3D). Following treatment, Treg cell numbers in the IL-10-DCs + CTLA4-Ig group were significantly higher compared with the IL-10-DCs and CTLA4-Ig groups (Fig. 3D).

Following intervention, the Th17/Treg cell ratio in the IL-10-DC, CTLA4-Ig and IL-10-DCs + CTLA4-Ig groups was significantly lower compared with the PBS group $(\mathrm{P}<0.05)$ and significantly higher compared with the normal group $(\mathrm{P}<0.05$; Fig. 4). The Th17/Treg cell ratio in the IL-10-DCs + CTLA4-Ig group was much lower compared with the IL-10-DC and CTLA4-Ig groups (Fig. 4). These results suggest that immune 
A

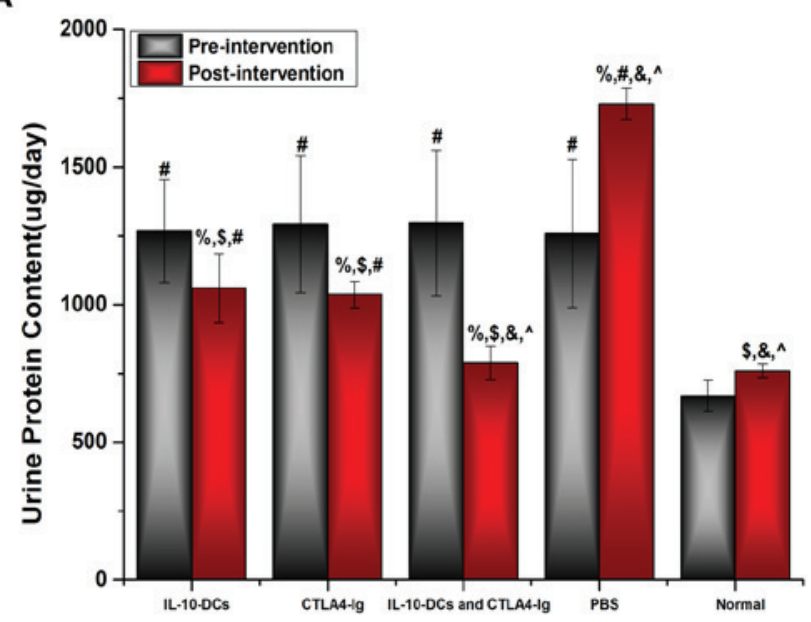

C

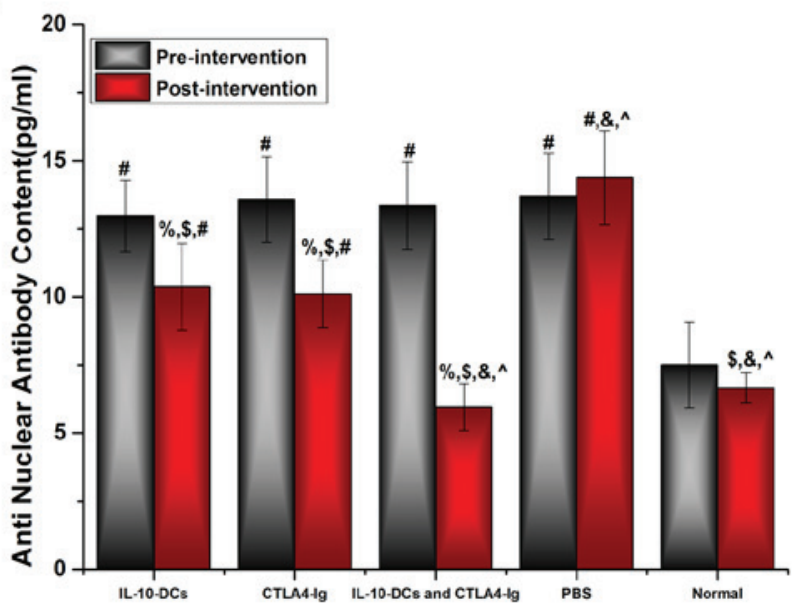

B



D

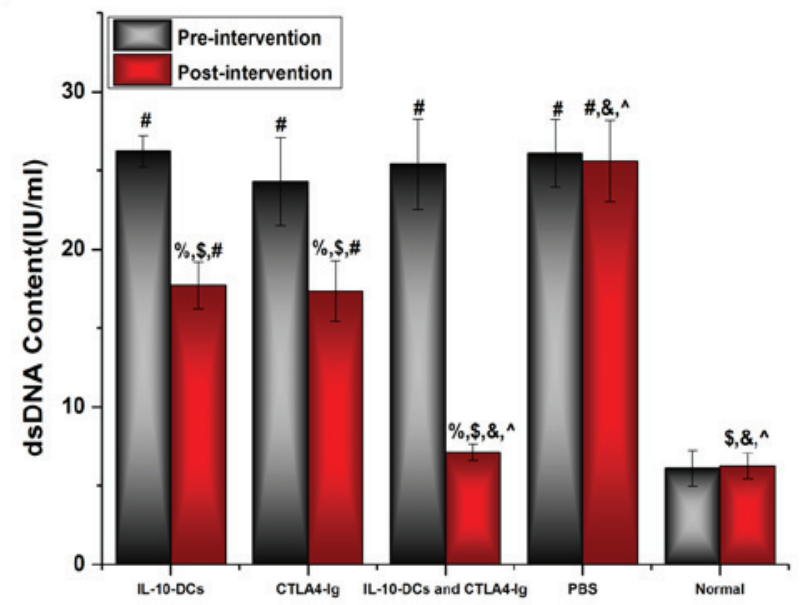

Figure 2. Immune tolerance is induced by IL-10-DCs and CTLA4-Ig. (A) Urine protein, (B) IL-17A, (C) ANA and (D) dsDNA levels in mice pre- and post-intervention. IL, interleukin; DCs, dendritic cells; CTLA4-Ig, cytotoxic T lymphocyte antigen 4-immunoglobulin; ANA, anti-nuclear antibody; ds, double stranded; Normal, untreated $\mathrm{C} 57 \mathrm{Bl} / 6 \mathrm{~J}$ mice. ${ }^{\%} \mathrm{P}<0.05$ vs. the same group pre-intervention, ${ }^{\$} \mathrm{P}<0.05$ vs. the PBS group post-intervention, ${ }^{\#} \mathrm{P}<0.05$ vs. the normal group, ${ }^{\circledR} \mathrm{P}<0.05$ vs. the IL-10-DCs group, ${ }^{\wedge} \mathrm{P}<0.05$ vs. the CTLA4-Ig group.

tolerance was induced by the administration of IL-10-DCs and CTLA4-Ig in mice with SLE.

\section{Discussion}

The present study aimed to investigate DC-induced immune tolerance in mice with SLE, an effect that was amplified by the administration of CTLA4-Ig. In vitro, lower levels of MHC II, CD40, CD80, and CD86 were expressed by IL-10-treated DCs compared with non-treated cells, indicating that the process of maturation was prevented. In the in vivo study, administering mice with SLE with IL-10-treated DCs reduced the levels of urine protein, ANA, dsDNA and IL-17A. Furthermore, treatment with IL-10-treated DCs decreased the proportion of Th17 cells and increased the proportion of $\mathrm{CD} 4^{+} \mathrm{Foxp} 3^{+}$Treg cells, suggesting that immune tolerance was induced by immature DCs in mice with SLE. Coadministration with IL-10-DCs and CTLA4-Ig resulted in a greater tolerance-inducing effect compared with IL-10-DCs or CTLA4-Ig treatment alone.

To prevent DCs from maturing, IL-10 was added into the culture medium in vitro. DCs are APCs that are specialized to regulate $\mathrm{T}$ cell immunity, including activation of $\mathrm{T}$ cells and maintenance of peripheral tolerance (30), and the function of DCs is dependent on their state of activation and differentiation (31). Mature DCs are able to induce the development of T effector cells (32), whereas immature DCs are associated with the maintenance of immunological tolerance (33). In an in vitro culture system, FBS acts as an antigen to facilitate DC maturation (34). For the D6-DCs group, the expression of surface markers, including the immune response molecules MHC II, CD40, CD86 and CD80, was evident in $25-30 \%$ of mature DCs. However, in the D9-DCs group this expression increased to $40 \%$ under the same conditions, indicating that DCs differentiate into mature cells when cultured for an extended period. As an immunomodulatory cytokine that inhibits DC function, IL-10 is a major factor that prevents the differentiation of DCs from monocytes (35-37). Furthermore, IL-10 is able to inhibit receptor-mediated macropinocytosis and endocytosis following exposure to a soluble immunogen (36), and serves an important role in immune tolerance (38). In addition to exogenous IL-10, autocrine IL-10 prevents spontaneous DC maturation in vitro, limits lipopolysaccharide- and CD40-mediated maturation, and increases IL-10 production by DCs (39). IL-10 secretion therefore assists in maintaining the immature state of DCs. 
A
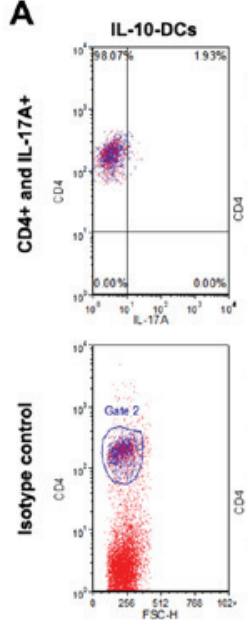

C
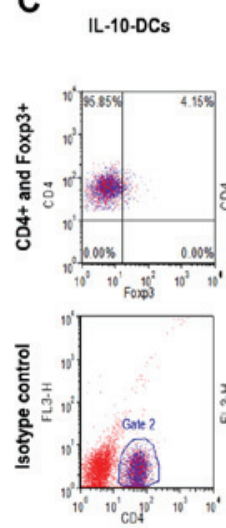

CTLA4-Ig
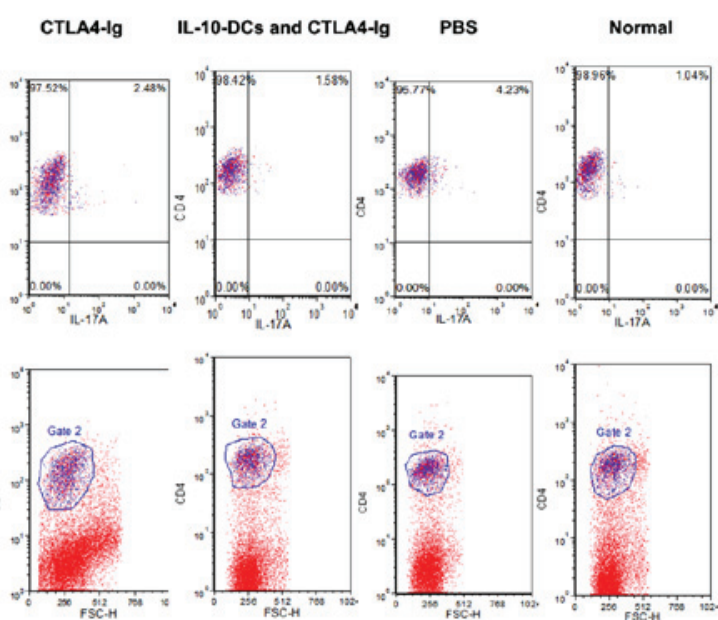

CTLA4-Ig
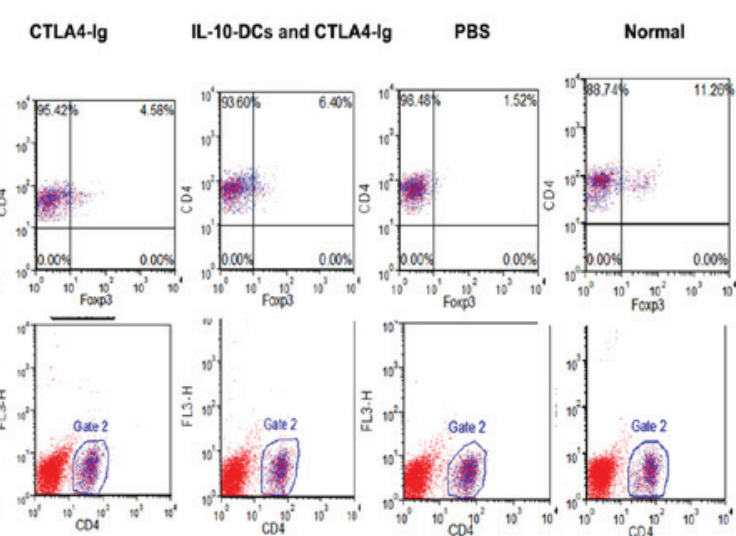

B

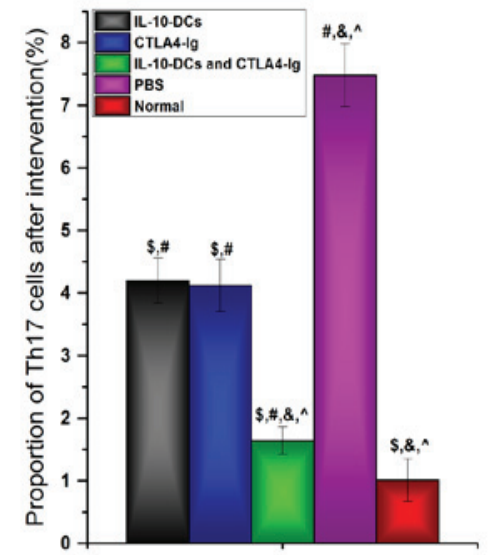

$\mathbf{D}$

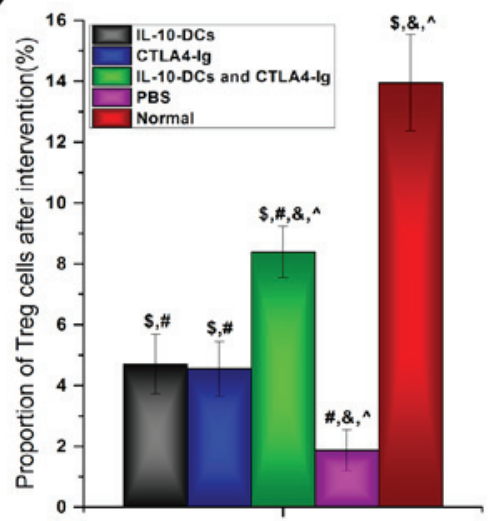

Figure 3. Proportion of Th17 and Treg cells as analyzed by flow cytometry. (A) CD4+IL-17A ${ }^{+}$cells were identified as the Th17 cell subset and (B) analyzed. (C) $\mathrm{CD}^{+}{ }^{+}$Foxp $^{+}$cells were identified as the Treg cell subset and (D) analyzed. Th, T helper cells; Treg, regulatory T cells; CD, cluster of differentiation; IL, interleukin; Foxp3, forkhead box protein P3; DCs, dendritic cells; CTLA4-Ig, cytotoxic T lymphocyte antigen 4-immunoglobulin; PE, phycoerythrin; Normal, untreated $\mathrm{C} 57 \mathrm{Bl} / 6 \mathrm{~J}$ mice. ${ }^{\$} \mathrm{P}<0.05$ vs. the $\mathrm{PBS}$ group post-intervention, ${ }^{\#} \mathrm{P}<0.05$ vs. the normal group, ${ }^{\&} \mathrm{P}<0.05$ vs. the IL-10-DCs group, ${ }^{\wedge} \mathrm{P}<0.05$ vs. the CTLA4-Ig group.

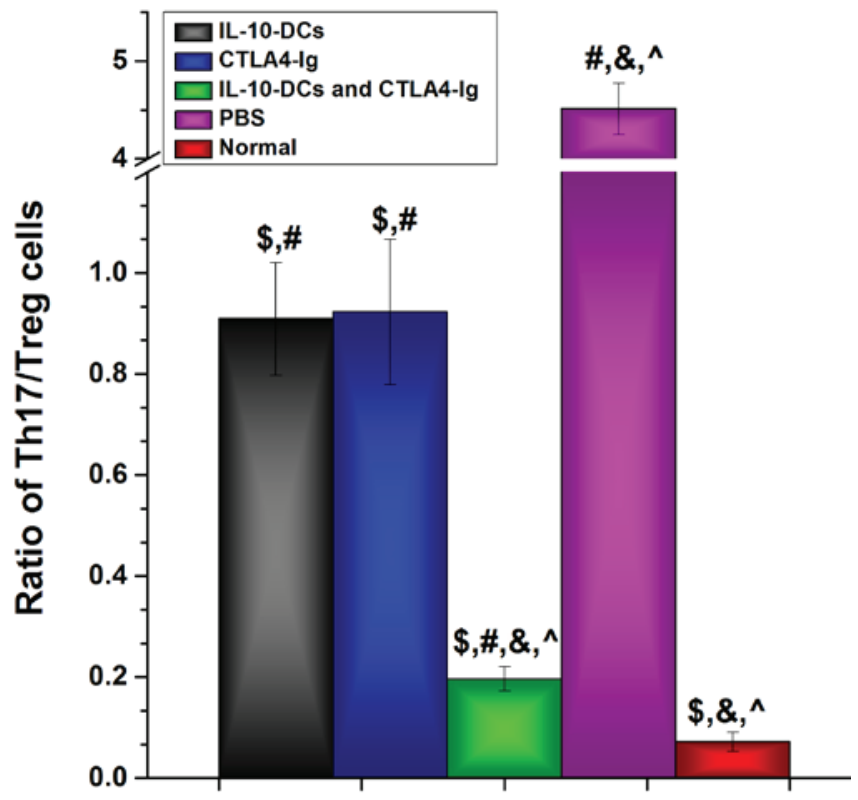

Figure 4. IL-10-DC and CTLA4-Ig intervention lowers the Th17/Treg cell ratio. Th, T helper cells; Treg, regulatory T cells; IL, interleukin; DCs, dendritic cells; CTLA4-Ig, cytotoxic T lymphocyte antigen 4-immunoglobulin. ${ }^{\$} \mathrm{P}<0.05$ vs. the PBS group post-intervention, ${ }^{\#} \mathrm{P}<0.05$ vs. the normal group, ${ }^{\circledR} \mathrm{P}<0.05$ vs. the IL-10-DCs group, ${ }^{\wedge} \mathrm{P}<0.05$ vs. the CTLA4-Ig group.
The capacity of immature DCs and CTLA4-Ig to induce immune tolerance was further explored in mice with SLE. The results demonstrated that immune tolerance was strongly induced, as evidenced by lower expression of urine protein, ANA, dsDNA and IL-17A, as well as a decrease in Th17 cells and an increase in $\mathrm{CD}^{+}{ }^{+} \mathrm{Foxp} 3^{+}$Treg cells. Immature DCs are considered to be prototypic tolerogenic DCs due to their poor $\mathrm{T}$ cell stimulatory capacity (40). Immature DCs have therefore been utilized to induce immunosuppression in mammals with specific malignancies or autoimmune disease, as well as following transplantation (41-43). Several methods, including co-culture with marrow stromal cells (42), anti-vascular endothelial growth factor antibody (44) and IL-10 (45), have been used to maintain the immature state of DCs. IL-10-treated DCs induce alloantigen-specific $\mathrm{T}$ cell hyporesponsiveness and are also able to inhibit antigen-specific immunological responses $(46,47)$, thereby prolonging liver allograft survival and enhancing immune tolerance (48). Furthermore, in the present study, CTLA4-Ig amplified the immune tolerance of IL-10-treated DCs in vivo. The interaction of CD80 and CD86 molecules expressed on DCs with CD28 molecules expressed on T cells is crucial for inducing $\mathrm{T}$ cell immune responses (49). CTLA4-Ig blocks CD28-mediated co-stimulatory signaling to $\mathrm{T}$ cells to induce tolerance (50) and maintain the tolerogenic 
state of DCs (51). It has previously been demonstrated that the $\mathrm{CD} 4{ }^{+} \mathrm{CD} 25^{+} \mathrm{Foxp} 3^{+}$Treg population in mouse joints and spleen is increased in CTLA4-Ig-treated collagen-induced arthritis model mice and that DCs are modified to become tolerogenic (52). However, there are few reports on the effects of co-injection with immature DCs and CTLA4-Ig in SLE. In the present study, the combination of immature DCs and CTLA4-Ig effectively induced immune tolerance in mice with SLE.

In summary, the results of the present study demonstrate that combined treatment with IL-10-treated immature DCs and CTLA4-Ig induces immune tolerance in mice with SLE. Co-injection of DCs and CTLA4-Ig may therefore have potential as a therapeutic strategy to promote immune tolerance, alleviate multiple organ dysfunction and improve the quality of life of patients with SLE.

\section{Acknowledgements}

The present study was supported by the National Natural Science Foundation of China (grant no. 81460475), Guangxi Natural Science Foundation (grant nos. 2013GXNSFDA253001 and 2010GXNSFA013186) and the Guangxi Health Department Key Project (grant no. Guiweizhong 200829).

\section{References}

1. Tsokos GC and Kammer GM: Molecular aberrations in human systemic lupus erythematosus. Mol Med Today 6: 418-424, 2000. 2. Fassbinder T, Saunders U, Mickholz E, Jung E, Becker H, Schluter B and Jacobi AM: Differential effects of cyclophosphamide and mycophenolate mofetil on cellular and serological parameters in patients with systemic lupus erythematosus. Arthritis Res Ther 17: 92, 2015.

3. Schiffer L, Sinha J, Wang X, Huang W, von Gersdorff G, Schiffer M, Madaio MP and Davidson A: Short term administration of costimulatory blockade and cyclophosphamide induces remission of systemic lupus erythematosus nephritis in NZB/W F1 mice by a mechanism downstream of renal immune complex deposition. J Immunol 171: 489-497, 2003.

4. Griffiths B, Emery P, Ryan V, Isenberg D, Akil M, Thompson R, Maddison P, Griffiths ID, Lorenzi A, Miles S, et al: The BILAG multi-centre open randomized controlled trial comparing ciclosporin vs azathioprine in patients with severe SLE. Rheumatology (Oxford) 49: 723-732, 2010.

5. Shen C, He Y, Cheng K, Zhang D, Miao S, Zhang A, Meng F, Miao F and Zhang J: Killer artificial antigen-presenting cells deplete alloantigen-specific $\mathrm{T}$ cells in a murine model of alloskin transplantation. Immunol Lett 138: 144-155, 2011.

6. Mozaffarian N, Wiedeman AE and Stevens AM: Active systemic lupus erythematosus is associated with failure of antigen-presenting cells to express programmed death ligand-1. Rheumatology (Oxford) 47: 1335-1341, 2008.

7. Sawla P, Hossain A, Hahn BH and Singh RP: Regulatory T cells in systemic lupus erythematosus (SLE); role of peptide tolerance. Autoimmun Rev 11: 611-614, 2012.

8. Smyth LA, Ratnasothy K, Moreau A, Alcock S, Sagoo P, Meader L, Tanriver Y, Buckland M, Lechler R and Lombardi G: Tolerogenic donor-derived dendritic cells risk sensitization in vivo owing to processing and presentation by recipient APCs. J Immunol 190: 4848-4860, 2013.

9. Spisek R, Bretaudeau L, Barbieux I, Meflah K and Gregoire M: Standardized generation of fully mature p70 IL-12 secreting monocyte-derived dendritic cells for clinical use. Cancer Immunol Immunother 50: 417-427, 2001.

10. Real E, Kaiser A, Raposo G, Amara A, Nardin A, Trautmann A and Donnadieu E: Immature dendritic cells (DCs) use chemokines and intercellular adhesion molecule (ICAM)-1, but not DC-specific ICAM-3-grabbing nonintegrin, to stimulate CD4+ T cells in the absence of exogenous antigen. J Immunol 173: 50-60, 2004.
11. Tang LL, Zhang Z, Zheng JS, Sheng JF and Liu KZ: Phenotypic and functional characteristics of dendritic cells derived from human peripheral blood monocytes. J Zhejiang Univ Sci B 6: 1176-1181, 2005.

12. Kalinski P, Schuitemaker JH, Hilkens CM, Wierenga EA and Kapsenberg ML: Final maturation of dendritic cells is associated with impaired responsiveness to IFN-gamma and to bacterial IL-12 inducers: Decreased ability of mature dendritic cells to produce IL-12 during the interaction with Th cells. J Immunol 162: 3231-3236, 1999.

13. Gombos I, Detre C, Vámosi G and Matkó J: Rafting MHC-II domains in the APC (presynaptic) plasma membrane and the thresholds for T-cell activation and immunological synapse formation. Immunol Lett 92: 117-124, 2004.

14. Cochand L, Isler P, Songeon F and Nicod LP: Human lung dendritic cells have an immature phenotype with efficient mannose receptors. Am J Respir Cell Mol Biol 21: 547-554, 1999.

15. Janikashvili N, Bonnotte B, Katsanis E and Larmonier N: The dendritic cell-regulatory $\mathrm{T}$ lymphocyte crosstalk contributes to tumor-induced tolerance. Clin Dev Immunol 2011: 430394, 2011.

16. Choi KH, Choi BH, Park SR, Kim BJ and Min BH: The chondrogenic differentiation of mesenchymal stem cells on an extracellular matrix scaffold derived from porcine chondrocytes. Biomaterials 31: 5355-5365, 2010.

17. Lutz MB, Suri RM, Niimi M, Ogilvie AL, Kukutsch NA, Rössner S, Schuler G and Austyn JM: Immature dendritic cells generated with low doses of GM-CSF in the absence of IL-4 are maturation resistant and prolong allograft survival in vivo. Eur J Immunol 30: 1813-1822, 2000.

18. Lott DG, Dan O, Lu L and Strome M: Decoy NF-kappaB fortified immature dendritic cells maintain laryngeal allograft integrity and provide enhancement of regulatory $\mathrm{T}$ cells. Laryngoscope 120: 44-52, 2010.

19. Liu QL, Wang YS and Wang JX: Effect of growth hormone on the immune function of dendritic cells. Chin Med J (Engl) 123: 1078-1083, 2010

20. Liu WH,Liu JJ, Wu J,Zhang LL, Liu F, Yin L, Zhang MM and Yu B: Novel mechanism of inhibition of dendritic cells maturation by mesenchymal stem cells via interleukin-10 and the JAK1/STAT3 signaling pathway. PLoS One 8: e55487, 2013.

21. Commeren DL, Van Soest PL, Karimi K, Löwenberg B, Cornelissen JJ and Braakman E: Paradoxical effects of interleukin-10 on the maturation of murine myeloid dendritic cells. Immunology 110: 188-196, 2003.

22. Lee WC, Qiani S, Wan Y, Li W, Xing Z, Gauldie J, Fung JJ, Thomson AW and Lu L: Contrasting effects of myeloid dendritic cells transduced with an adenoviral vector encoding interleukin-10 on organ allograft and tumour rejection. Immunology 101: 233-241, 2000.

23. Oberholzer A, Oberholzer C, Efron PA, Scumpia PO, Uchida T, Bahjat K, Ungaro R, Tannahill CL, Murday M, Bahjat FR, et al: Functional modification of dendritic cells with recombinant adenovirus encoding interleukin 10 for the treatment of sepsis. Shock 23: 507-515, 2005.

24. Coates PT, Krishnan R, Kireta S, Johnston J and Russ GR: Human myeloid dendritic cells transduced with an adenoviral interleukin-10 gene construct inhibit human skin graft rejection in humanized NOD-scid chimeric mice. Gene Ther 8: 1224-1233, 2001.

25. Müller G, Müller A, Tüting T, Steinbrink K, Saloga J, Szalma C, Knop J and Enk AH: Interleukin-10-treated dendritic cells modulate immune responses of naive and sensitized $\mathrm{T}$ cells in vivo. J Invest Dermatol 119: 836-841, 2002.

26. Mok MY: Tolerogenic dendritic cells: Role and therapeutic implications in systemic lupus erythematosus. Int J Rheum Dis 18: 250-259, 2015.

27. Oracki SA, Tsantikos E, Quilici C, Light A, Schmidt T, Lew AM, Martin JE, Smith KG, Hibbs ML and Tarlinton DM: CTLA4Ig alters the course of autoimmune disease development in Lyn-/mice. J Immunol 184: 757-763, 2010.

28. Badell IR, Russell MC, Cardona K, Shaffer VO, Turner AP, Avila JG, Cano JA, Leopardi FV, Song M, Strobert EA, et al: CTLA4Ig prevents alloantibody formation following nonhuman primate islet transplantation using the CD40-specific antibody 3A8. Am J Transplant 12: 1918-1923, 2012.

29. Zhou Y, Leng X, Luo S, Su Z, Luo X, Guo H, Mo C, Zou Q, Liu Y and Wang Y: Tolerogenic dendritic cells generated with tofacitinib ameliorate experimental autoimmune encephalomyelitis through modulation of Th17/Treg balance. J Immunol Res 2016: 5021537, 2016. 
30. Ureta G, Osorio F, Morales J, Rosemblatt M, Bono MR and Fierro JA: Generation of dendritic cells with regulatory properties. Transplant Proc 39: 633-637, 2007.

31. Mahnke K, Schmitt E, Bonifaz L, Enk AH and Jonuleit H: Immature, but not inactive: The tolerogenic function of immature dendritic cells. Immunol Cell Biol 80: 477-483, 2002.

32. Laborde EA, Vanzulli S, Beigier-Bompadre M, Isturiz MA, Ruggiero RA, Fourcade MG, Catalan Pellet AC, Sozzani S and Vulcano M: Immune complexes inhibit differentiation, maturation, and function of human monocyte-derived dendritic cells J Immunol 179: 673-681, 2007.

33. Griffiths KL and O'Neill HC: Dendritic cells as immune regulators: The mouse model. J Cell Mol Med 12: 1909-1914, 2008.

34. Röner S, Zinser E, Menges M, Wiethe C, Littmann L, Hänig J, Steinkasserer A and Lutz MB: Minor role of bystander tolerance to fetal calf serum in a peptide-specific dendritic cell vaccine model against autoimmunity: Comparison with serum-free cultures. J Immunother 31: 656-664, 2008.

35. Allavena P, Piemonti L, Longoni D, Bernasconi S, Stoppacciaro A Ruco L and Mantovani A: IL-10 prevents the differentiation of monocytes to dendritic cells but promotes their maturation to macrophages. Eur J Immunol 28: 359-369, 1998.

36. Morel AS, Quaratino S, Douek DC and Londei M: Split activity of interleukin-10 on antigen capture and antigen presentation by human dendritic cells: Definition of a maturative step. Eur J Immunol 27: 26-34, 1997.

37. Buelens C, Verhasselt V, De Groote D, Thielemans K, Goldman M and Willems F: Interleukin-10 prevents the generation of dendritic cells from human peripheral blood mononuclear cells cultured with interleukin-4 and granulocyte/macrophage-colony-stimulating factor. Eur J Immunol 27: 756-762, 1997.

38. Akdis CA and Akdis M: Mechanisms of immune tolerance to allergens: Role of IL-10 and Tregs. J Clin Invest 124: 4678-4680, 2014.

39. Corinti S, Albanesi C, la Sala A, Pastore S and Girolomoni G: Regulatory activity of autocrine IL-10 on dendritic cell functions. J Immunol 166: 4312-4318, 2001.

40. Stoop JN, Harry RA, von Delwig A, Isaacs JD, Robinson JH and Hilkens CM: Therapeutic effect of tolerogenic dendritic cells in established collagen-induced arthritis is associated with a reduction in Th17 responses. Arthritis Rheum 62: 3656-3665, 2010.

41. Oh BC, Lee HM, Lim DP, Cho JJ, Lee G, Lee DS and Lee JR Effect of immature dendritic cell injection before heterotropic cardiac allograft. Transplant Proc 38: 3189-3192, 2006.
42. Yin W, Ouyang S, Li Y, Xiao B and Yang H: Immature dendritic cell-derived exosomes: A promise subcellular vaccine for autoimmunity. Inflammation 36: 232-240, 2013.

43. Bloy N, Pol J, Aranda F, Eggermont A, Cremer I, Fridman WH, Fučíková J, Galon J, Tartour E, Spisek R, et al: Trial watch: Dendritic cell-based anticancer therapy. Oncoimmunology 3 : e963424, 2014.

44. Osada T, Chong G, Tansik R, Hong T, Spector N, Kumar R, Hurwitz HI, Dev I, Nixon AB, Lyerly HK, et al: The effect of anti-VEGF therapy on immature myeloid cell and dendritic cells in cancer patients. Cancer Immunol Immunother 57: 1115-1124, 2008.

45. Ma ZH, Lu H, Lu Q, Yao ZF and Han Y: CD1d blockade suppresses the capacity of immature dendritic cells to prime allogeneic T cell response. J Surg Res 183: 894-899, 2013.

46. Enk AH, Angeloni VL, Udey MC and Katz SI: Inhibition of Langerhans cell antigen-presenting function by IL-10. A role for IL-10 in induction of tolerance. J Immunol 151: 2390-2398, 1993.

47. Steinbrink K, Jonuleit H, Müller G, Schuler G, Knop J and Enk AH: Interleukin-10-treated human dendritic cells induce a melanoma-antigen-specific anergy in CD8(+) T cells resulting in a failure to lyse tumor cells. Blood 93: 1634-1642, 1999.

48. Chen L, Zheng L, He W, Qiu M, Gao L, Liu J and Huang A Cotransfection with IL-10 and TGF- $\beta 1$ into immature dendritic cells enhances immune tolerance in a rat liver transplantation model. Am J Physiol Gastrointest Liver Physiol 306: G575-G581, 2014.

49. Bakdash G, Sittig SP, van Dijk T, Figdor CG and de Vries IJ: The nature of activatory and tolerogenic dendritic cell-derived signal II. Front Immunol 4: 53, 2013.

50. Linsley PS and Nadler SG: The clinical utility of inhibiting CD28-mediated costimulation. Immunol Rev 229: 307-321, 2009.

51. Tian M, Lv Y, Zhai C, Zhu H, Yu L and Wang B: Alternative immunomodulatory strategies for xenotransplantation: CD80/CD86-CTLA4 pathway-modified immature dendritic cells promote xenograft survival. PLoS One 8: e69640, 2013.

52. Ko HJ, Cho ML, Lee SY, Oh HJ, Heo YJ, Moon YM, Kang CM, Kwok SK, Ju JH, Park SH, et al: CTLA4-Ig modifies dendritic cells from mice with collagen-induced arthritis to increase the CD $4+C D 25+F o x p 3+$ regulatory $\mathrm{T}$ cell population. J Autoimmun 34: 111-120, 2010. 